\title{
A Markov Model Approach Assessing the Cost of Illness of Generalized Anxiety Disorder in Canada
}

Basil G. Bereza • Márcio Machado • Manny Papadimitropoulos •

Beth Sproule $\cdot$ Arun V. Ravindran · Thomas R. Einarson

To view enhanced content go to www.neurologytherapy-open.com

Received: February 21, 2012 / Published online: June 7, 2012

(c) The Author(s) 2012. This article is published with open access at Springerlink.com

\section{ABSTRACT}

Introduction: Generalized anxiety disorder (GAD) is a chronic disease with waxing and

B. G. Bereza $(\bowtie) \cdot$ M. Machado .

M. Papadimitropoulos - B. Sproule - T. R. Einarson Leslie Dan Faculty of Pharmacy,

University of Toronto, 144 College Street,

Toronto, ON M5S 3M2, Canada

e-mail: basil.bereza@utoronto.ca

\section{Machado}

Toronto Health Technology Assessment

Collaborative, University of Toronto,

Toronto, ON, Canada

M. Papadimitropoulos

Eli Lilly Canada Inc., 3650 Danforth Avenue,

Toronto, ON M1N 2E8, Canada

B. Sproule · A. V. Ravindran

Centre for Addiction and Mental Health,

250 College Street, Toronto,

ON M5T 1R8, Canada

A. V. Ravindran

Department of Psychiatry, University of Toronto,

33 Russell Street, Toronto, ON M5S 2S1, Canada

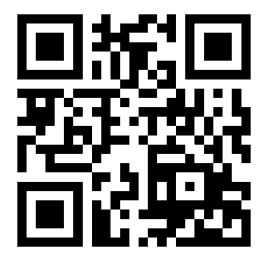

Enhanced content for this article is

available on the journal web site:

www.neurologytherapy-open.com waning of symptoms. This is the first comprehensive economic model developed to reflect the nature and course of GAD.

Methods: An incidence-based probabilistic Markov model was developed reflecting nine GAD health states (HS): clinical assessments (three HS), maintenance therapies (four HS), discontinuation (one HS), and death (one HS). A probability curve of the GAD onset (ages 18-80) determined entry into the model and assumed patients retained the diagnoses until death. Canadian Psychiatric Association (CPA) guidelines determined pharmacotherapy, with revisions/validation by an expert panel. Direct costs (clinician, pharmacotherapy, hospitalization) were retrieved from government publications. Remission was based on pooledanalysis of CPA-cited evidence. Remaining clinical rates, absenteeism, and hospitalization were retrieved from the literature. Direct costs were attributed throughout the model except for the discontinuation and death HS. Indirect costs (wage rate) were retrieved from government publications and the literature (absenteeism), and were attributed to patients with GAD $\leq 65$ years of age. Results were discounted at 5\% and results expressed in 2008 Canadian dollars. 
Results: The mean lifetime cost of illness (COI) was estimated to be $\$ 31,213$ (SD $\$ 9,100$ ) per patient. The cost of absenteeism accounted for $96 \%$ of the mean COI. The mean age of onset was 31 years and approximately 19\% did not respond to pharmacotherapy. Over $85 \%$ of patients discontinued treatment by the fourth cycle (2nd year of therapy). Over the course of the model, a mean of $53 \%$ of patients relapsed, with an average rate of 0.79 relapses per patient. On average and over a lifetime, the disorder went unmanaged over a period of 14 (SD 9) years. The model was most sensitive to absenteeism.

Conclusion: GAD is a costly disease with a lifetime COI $<\$ 32 \mathrm{k} /$ patient, with absenteeism exerting a significant impact.

Keywords: Absenteeism; Cost of illness; Decision model; Economics; Generalized anxiety; Markov model; Pharmacotherapy

\section{INTRODUCTION}

The resources needed to meet the demand for healthcare services, including mental health, are scarce and are becoming more so. Decision-makers increasingly rely on economic evaluations to help make choices under budget constraints [1]. Generalized anxiety disorder (GAD) imposes a significant individual and societal burden; hampering economic productivity and contributing to healthcare service utilization [2-4]. The estimated lifetime prevalence of GAD ranges between 2.4 and 5.7\% in the general population $[2,3,5-7]$. The clinical course for GAD is difficult to map due to the lack of prospective epidemiologic studies [8]. However, retrospective studies indicate that GAD is a chronic disease with fluctuating symptoms, characterized by excessive, uncontrolled, and often irrational and disproportionate concern about everyday issues [8-11]. While the management of GAD includes both psychological and pharmacologic treatment, either alone or in combination, most patients are treated with pharmacotherapy because of limited access to cognitive behavior therapy (CBT) [9]. Furthermore, there is insufficient evidence for the combination to be superior to either treatment form alone [12].

Economic evaluations of healthcare services or products may be categorized as either "full" or "partial" depending on the scope of analysis. Examples of full economic evaluations include cost-benefit analysis (CBA), cost-effectiveness analysis (CEA), cost-minimization analysis (CMA), and cost-utility analysis (CUA). Parameters of an economic evaluation include costs, consequences, and the subsequent comparison of those costs and consequences through an incremental cost-effectiveness ratio (ICER) between targeted comparators. Studies limited to the economic component of a full economic evaluation have been referred to as partial economic evaluations. Examples of such studies include cost-description studies (cost or burden of illness, resource utilization), costoutcome description studies (single service or program), and cost-comparison. All of these approaches have been used previously in psychiatry.

Despite the chronicity of the disorder, longitudinal economic evaluations related to GAD have been limited to time periods of 18 months or less; failing to reflect the protracted course of the disorder and leaving the lifetime cost of the disorder to be determined [4]. The CEA related to GAD were designed using summary population data or conventional decision-tree models and were often less than a year in duration [4]. Furthermore, previous cost of illness (COI) studies of GAD focused solely on its direct 
economic impact on healthcare systems, and did not take into consideration the disorder's impact on productivity [4]. The purpose of this study was to develop a dynamic decision model, reflecting the nature of the disorder, and to quantify its lifetime COI per patient from a societal perspective in Canada.

Decision analysis is a mathematical model that incorporates a systematic and quantitative approach to decision-making under conditions of uncertainty. The framework for decision analysis is based on research by von Neumann and Morgenstern [13], known as the theory of expected utility. The premise of this theory is that rational decision makers would choose an option that maximizes their expected utility. However, given the abundance or complexity of information, the ability of decision-makers to process and arrive at a rational decision may be subject to bias. The structured approach afforded by decision analysis models enables the decision to be based on a more extensive range of data and a formal synthesis of the information [14], thereby, supplementing reasoning abilities and reducing bias.

\section{METHODS}

\section{Subjects}

The target population was adults (aged $18-80$ years) with a primary diagnosis of GAD fulfilling the Diagnostic and Statistical Manual IV (DSM-IV) or International Classification of Disease-10 (ICD-10) criteria. The choice of the lower age limit corresponded to the age at which patients were usually recruited into the Canadian Psychiatric Association (CPA)-cited evidence [12]. Canadian life expectancy published by Statistics Canada set the upper age boundary [15].
Although several studies compare suicidal ideation in a GAD cohort to a co-morbid GAD cohort and other anxiety disorder, none report raw data of suicide rates attributable to GAD. The age-specific attrition rate infers that these rates include suicide rates from a population that includes all mental disorders. Therefore, the net increase of suicide as a direct result of GAD is hypothesized to be negligible for the purposes of this study.

\section{Pharmacoeconomic Model}

A decision analytic framework was used to model the relationship between GAD, the management of the disorder, and the cost consequences of these assumptions. TreeAge ${ }^{\circledR}$ Pro Suite 2009 (TreeAge Software Inc., Williamstown, MA, USA) software was used to develop an incidence-based, probabilistic Markov model.

The analysis was undertaken to evaluate both direct and indirect costs to society. The former included family practice and specialist physician fees, drugs and drug dispensing fees, as well as the cost of hospital stay. The latter was estimated by measuring foregone wages due to absenteeism, which was also used as a proxy for valuation of leisure time or time lost for those not currently employed. The cost of absenteeism was not attributed to patients over the age of 65 years. Costs related to co-morbid psychiatric disorders, such as depression, or somatic conditions, such as irritable bowel syndrome (IBS), were not included in the analysis.

\section{Health States}

The model included nine health states (Table 1). Creation of these health states was guided by tolerance of medication and optimal pharmacotherapeutic management of GAD. 
Table 1 List and description of Markov health states

\begin{tabular}{|c|c|c|}
\hline Health state number & Health state descriptor & Patient description \\
\hline 1 (initial) & $\begin{array}{l}\text { Family physician assessment } \\
\text { (initial health state) }\end{array}$ & $\begin{array}{l}\text { Family practice physician initially diagnoses and treats } \\
\text { GAD with 1st line agents } \\
\text { May re-enter model after at least one cycle in treatment } \\
\text { discontinuation state }\end{array}$ \\
\hline 2 & Specialist assessment 2 nd line & $\begin{array}{l}\text { Treatment managed by a psychiatrist prescribing } 2 \text { nd } \\
\text { line treatment options (i.e., patient Intolerant to } 1 \text { st } \\
\text { line agents, or responded to } 1 \text { st line medication but not } \\
\text { remitted, or neither responded nor remitted to } 1 \text { st line } \\
\text { therapy) }\end{array}$ \\
\hline 3 & Specialist assessment 3rd line & $\begin{array}{l}\text { Treatment managed by a psychiatrist prescribing } 3 \text { rd line } \\
\text { or treatment-resistant options (i.e., intolerant or did } \\
\text { not respond to } 1 \text { st or } 2 \text { nd line pharmacotherapy) }\end{array}$ \\
\hline $4-7$ & Maintenance therapies & $\begin{array}{l}\text { Patients on maintenance therapy who have achieved } \\
\text { remission in } 1 \text { st line or } 2 \text { nd line health states } \\
\text { Patients who have achieved remission or response and } \\
\text { are maintained with 3rd line therapy }\end{array}$ \\
\hline 8 & Treatment discontinued & Patients discontinue therapy for any reason \\
\hline 9 & Absorbing state & Death-patients removed from model \\
\hline
\end{tabular}

$G A D$ generalized anxiety disorder

Health states also modeled patients who discontinued treatment or sought treatment anew. Patients entered the model once diagnosed with GAD by a physician in family practice. Upon suboptimal response (to firstline treatment), patients were assessed by a psychiatrist to determine appropriate therapeutic options. Four other health states modeled patients on their respective maintenance therapy. "Death" was the absorbing state. A "bubble" diagram depicting the health states and transitions among the health states is presented in Fig. 1. The length of time that patients' remained in the model was based on their life expectancy from the onset of illness. The distribution of patients' ages at disease onset was based on peer-reviewed literature [16].

\section{Patient Pathways and Cycle Length}

Within each health state, a probability matrix was embedded to describe pathways patients may have taken while in that health state. The matrix within each health state, with the exception of "death," began with the application of an attrition rate that was equivalent to the probability of death from all causes, allowing for patients to exit the model. Additional pathways included change of therapy, dose titration, treatment response or discontinuation, and disease remission or relapse. The attrition rate was derived from Statistics Canada age-adjusted life tables for 2000-2002 $[17,18]$. The cycle length of 6 months was based on the treatment algorithm recommended by the CPA as well as expert opinion [12]. An example of a decision tree is illustrated in Fig. 2. 


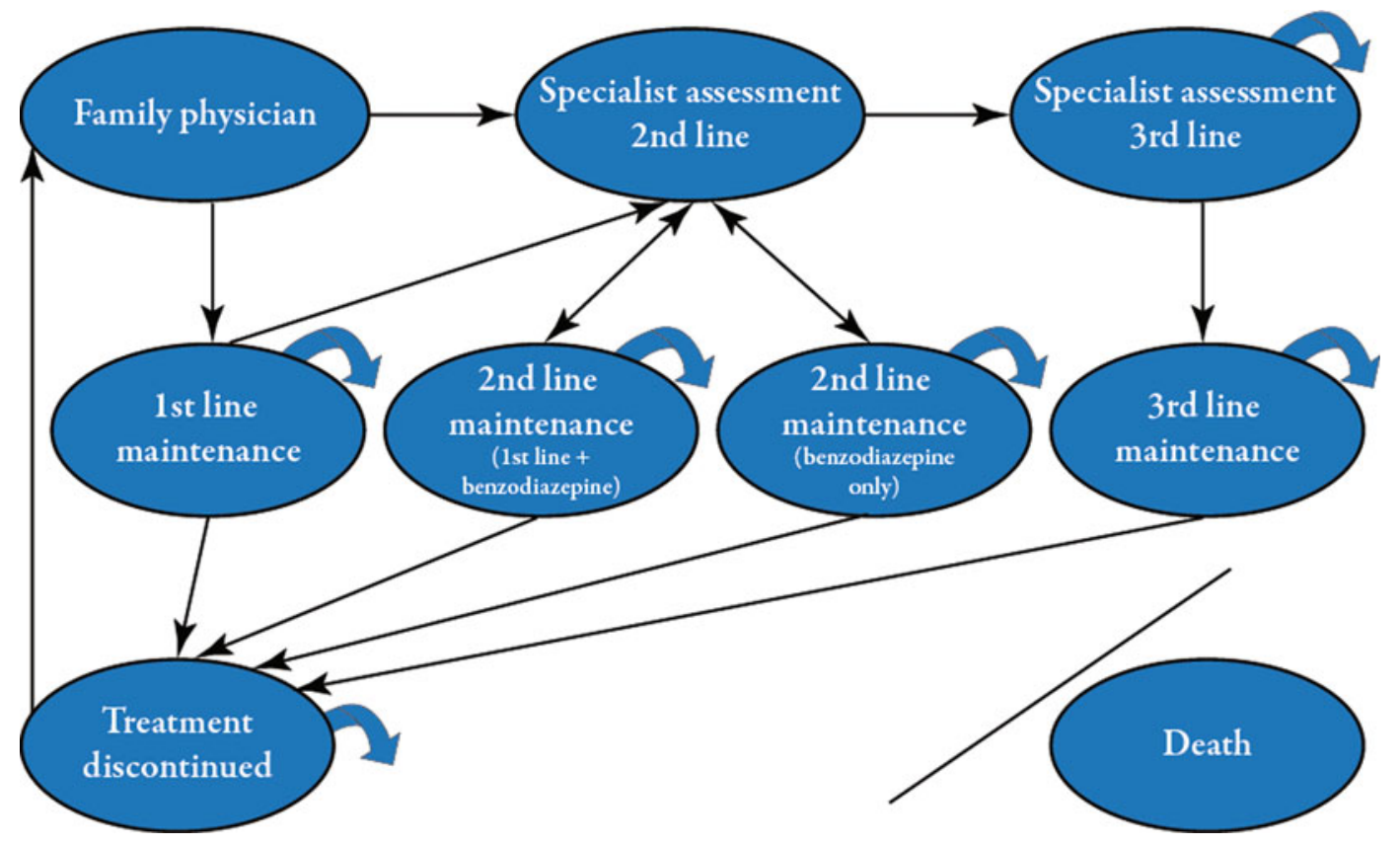

Fig. 1 Bubble diagram showing the health states and transition pathways for the Markov Model

\section{Management of GAD}

Pharmacotherapeutic choices for the management of GAD were based on CPA guidelines [12] as well as expert opinion. The reference case scenario considered pharmacotherapeutic management of GAD. First-line therapy was either a selective serotonin re-uptake inhibitor (SSRI) or serotonin-norepinephrine re-uptake inhibitor (SNRI). Second-line therapy was either a firstline agent augmented with a benzodiazepine or a benzodiazepine as monotherapy. Adjunctive olanzapine or risperidone, mirtazapine, trazodone, and citalopram were recommended as third-line options or for treatment-resistance individuals [12]. Dosing information was taken from the product monographs, peer-review literature, or CPA-cited evidence [12, 19-30].

Several second and third-line agents recommended by the guidelines were not included in this study due to uncommon use in clinical practice, often due to modest efficacy, lack of approved coverage, or both (e.g., pregabalin, bupropion, hydroxyzine). Buspirone has limited use due to reduced efficacy in patients who have previously been treated with benzodiazepines [12]. Imipramine is not used routinely due to increased toxicity risks [12].

The CPA guidelines do not provide a recommendation for the combination of CBT and pharmacotherapeutic agents, citing a lack of evidence [23-25]. However, an estimated $23 \%$ of patients with current anxiety are treated with a combination of medication and counseling [31]. The combination of CBT with pharmacotherapy was considered in a sensitivity (scenario) analysis.

\section{Clinical Variables}

The clinical rates used in this model are listed in Table 2 [27, 32-37]. The probability of patients' inability to tolerate pharmacotherapy was based on peer-reviewed published literature [32, 38]. 


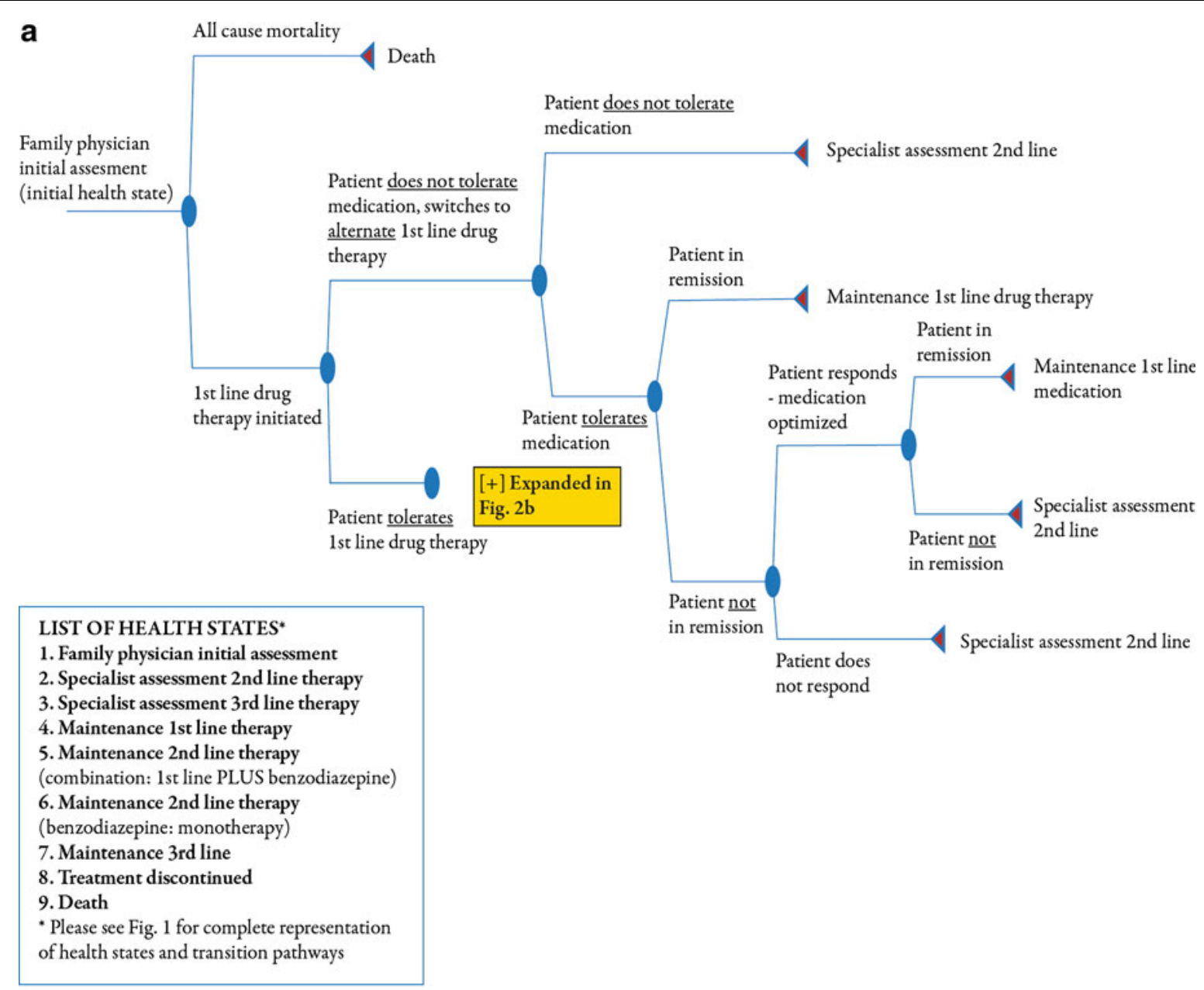

\section{b}

Expanded
from Fig. 2a

from Fig. 2a Patient in remission

Patient tolerates

1 st line drug

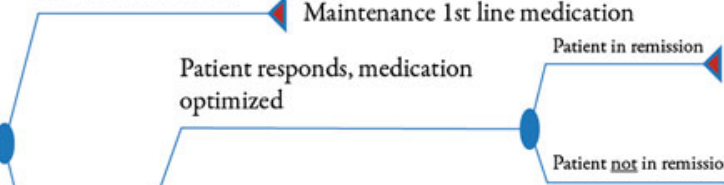

therapy

Patient does not tolerate alternated

Specialist assessment 2 nd line

Patient not

$\underline{1 \text { st line medication }}$ in remission

$\sqrt{\text { Specialist assessment 2nd line }}$

Patient does not respond, switches to alternate 1st line drug therapy

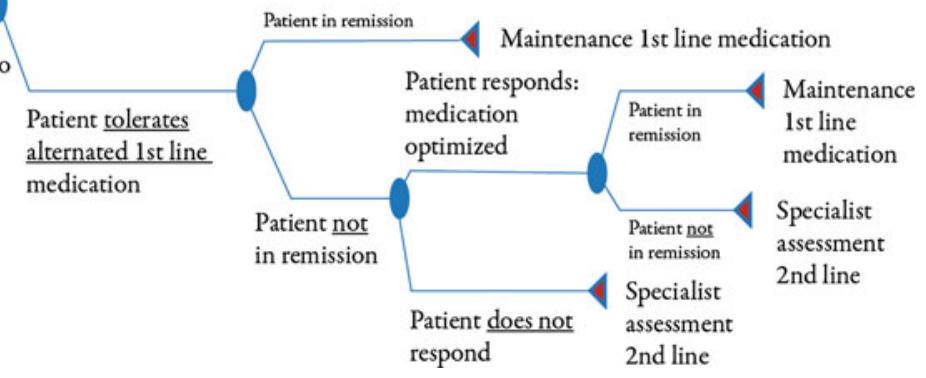

Fig. 2 Decision tree within the Family Physician Assessment Health State (a), decision tree (continued from a) within the Family Physician Assessment Health State (b) 
Table 2 Clinical variables and their value inputs

\begin{tabular}{|c|c|c|c|c|c|}
\hline \multirow[t]{2}{*}{ Clinical parameters } & \multicolumn{5}{|c|}{ Probabilities } \\
\hline & Mean & Low value & High value & Distribution & Source \\
\hline \multicolumn{6}{|l|}{ 1st line treatment } \\
\hline Inability to tolerate & 0.0900 & 0.0470 & 0.1470 & Triangular & Machado [32] \\
\hline Remission & 0.3970 & 0.3520 & 0.4410 & Triangular & Bereza [33] \\
\hline Response & 0.6772 & 0.6409 & 0.7136 & Triangular & Bereza [33] \\
\hline Discontinued treatment & 0.7138 & 0.7022 & 0.7266 & Triangular & Mullins [34] \\
\hline \multicolumn{6}{|l|}{ Benzodiazepine treatment } \\
\hline Inability to tolerate & 0.0730 & 0.0450 & 0.1010 & Triangular & Pooled results \\
\hline Remission & 0.5350 & 0.4400 & 0.6300 & Triangular & Bereza [33] \\
\hline Response & 0.5680 & 0.4640 & 0.6720 & Triangular & Bereza [33] \\
\hline Discontinued treatment & 0.5260 & 0.3630 & 0.6613 & Triangular & Ohayon [35] \\
\hline \multicolumn{6}{|c|}{ 1st line + benzodiazepine treatment } \\
\hline Inability to tolerate & 0.0900 & 0.0470 & 0.1470 & Triangular & Machado [32] \\
\hline Remission & 0.4100 & 0.3630 & 0.4560 & Triangular & Bereza [33] \\
\hline Response & 0.6430 & 0.6020 & 0.6840 & Triangular & Bereza [33] \\
\hline Discontinued treatment & 0.5260 & 0.3630 & 0.6613 & Triangular & Vasile [27] \\
\hline \multicolumn{6}{|l|}{ 3rd line treatment } \\
\hline Remission & 0.3570 & 0.2310 & 0.4820 & Triangular & Bereza [33] \\
\hline Response & 0.5490 & 0.3970 & 0.7020 & Triangular & Bereza [33] \\
\hline Discontinued treatment & 0.5260 & 0.3630 & 0.6613 & Triangular & Vasile [27] \\
\hline Relapse & 0.0250 & 0.0200 & 0.0500 & Triangular & Yonkers [36] \\
\hline Spontaneous remission & 0.2000 & 0.2250 & 0.2500 & Triangular & Ballenger [37] \\
\hline
\end{tabular}

Meta-analytic rates of adverse drug reactions reported in major depression were used as a proxy for GAD patients' inability to tolerate SSRI or SNRI agents. For benzodiazepines, data from CPA evidence were pooled using the dropout rate itself as an effect size and the binomial theorem to determine its variance; a technique described by Einarson [39]. The rates of patients' inability to tolerate medication were not required for patients treated with thirdline agents, as these rates were very infrequent. Remission and response rates were obtained from a previously published meta-analysis of CPA evidence [33]. Treatment discontinuation rates were based on peer-reviewed literature for each treatment line where possible [34, 35].

Relapse rates for this model were extrapolated for the assessed patients at 6 and 12 months intervals from data reported from the Harvard/Brown Anxiety Research Project (HARP), an observational, longitudinal study of patients with GAD [35]. A spontaneous remission rate of $22.5 \%$ was assigned to a 
cohort of patients who had discontinued treatment [37]. The rate was based on a consensus statement from the International Consensus Group on Depression and Anxiety. No evidence was given for this rate nor was spontaneous remission defined in their statement [37]. This rate was attributed to the "Treatment Discontinued" health state only. This model assumed that patients who did not "spontaneously remit" were experiencing GADrelated symptoms and may or may not decide to seek treatment.

\section{Resource Use and Costs}

\section{Physician Costs}

Economic input variables and their values for this study are presented in Table 3 [40-47]. Fees for family practice and psychiatry consultations were taken from the Government of Ontario's Ministry of Health and Long Term Care (MOHLTC) Schedule of Benefits for Physician Services [41]. Patients were subject to an initial physician assessment as well as follow-up visits to assess tolerance, response, or remission. Maintenance health states were attributed one follow-up visit per cycle. No physician costs were attributed to the "Treatment Discontinued" or "Death" states. For subgroup analysis, an additional ten sessions of CBT with a psychiatrist were attributed to patients in the "Family Physician" and "Specialist Assessment" second or third-line treatment health states.

\section{Drug Costs}

Costs for pharmacotherapy were based on the Government of Ontario, MOHLTC, Ontario Drug Benefit (ODB): formulary/Comparative Drug Index [44]. Costs for initial, maintenance, and optimized daily doses were considered separately. The dispensing fee was taken from the Government of Ontario,
MOHLTC, ODB: dispensing fee website [40]. Prescribed drugs were assumed to have been filled by a pharmacist in Ontario and handed to the patient. A dispensing fee was charged for the initial prescription, or when medication was titrated or switched. One prescription fee of $\$ 7$ Canadian dollars (CAD) was incurred for each 6-month cycle in a "Maintenance" health state.

\section{Hospitalization Costs}

The 2002 Health Canada report on mental illness in Canada reported that patients with anxiety disorders incurred on average ten hospitalization days in 1999 as a result of their disorder. This rate of utilization changed little between 1987 and 1999, ranging from 9.6 to 11.1 days [42]. Cost of hospitalization per day was an estimation of total acute care inpatient costs for 2004 from the Canadian Institute for Health Information (CIHI) database available on their web site [43]. Total hospitalization costs attributed to GAD were calculated by multiplying the number of hospitalization days by the total acute care inpatient cost. Inpatient costs were inflated to 2008 CAD using the Consumer Price Index [48].

\section{Indirect Costs}

Indirect costs were based on number of days absent, productivity lost from work in a given month, and the industrial wage rate [45]. The mean number of impaired days was derived from Kessler's study of two large surveys conducted in the US: the National Co-morbidity Survey and the Midlife Development in the US Survey. Kessler's study distinguished between productivity loss while at work and work days lost [45]. The weighted average from these surveys was approximately 2 days/month [45]. This rate was multiplied by the average industrial hourly wage rate for 2008 , of $\$ 21.08$, to calculate indirect costs, assuming an 8-h work day [45]. 
Table 3 Economic input and associated costs (in 2008 Canadian dollars)

\begin{tabular}{|c|c|c|c|c|c|}
\hline Variable & Distribution & Low & High & Value & Source \\
\hline \multicolumn{6}{|l|}{ Direct costs } \\
\hline \multicolumn{6}{|l|}{ Clinician/hospital charges } \\
\hline Pharmacist dispensing fee & Uniform & $\$ 6.00$ & $\$ 15.00$ & $\$ 10.50$ & MOHLTC: dispensing fees [40] \\
\hline $\begin{array}{l}\text { Initial assessment family } \\
\text { practice }\end{array}$ & Uniform & $\$ 42.53$ & $\$ 78.98$ & $\$ 60.75$ & MOHLTC: schedule of benefits [41] \\
\hline Follow-up family practice & Uniform & $\$ 21.25$ & $\$ 39.46$ & $\$ 30.35$ & MOHLTC: schedule of benefits [41] \\
\hline Initial assessment psychiatry & Uniform & $\$ 113.74$ & $\$ 211.22$ & $\$ 162.48$ & MOHLTC: schedule of benefits [41] \\
\hline Follow-up psychiatry & Uniform & $\$ 57.72$ & $\$ 107.19$ & $\$ 82.45$ & MOHLTC: schedule of benefits [41] \\
\hline $\begin{array}{l}\text { Hospitalization cost } \\
\text { (10-day period) }\end{array}$ & Uniform & $\$ 3,416.00$ & $\$ 6,340.00$ & $\$ 4,878.00$ & Health Canada [42]; CIHI [43] \\
\hline \multicolumn{6}{|c|}{ Pharmacotherapy (mean daily cost) } \\
\hline Initial 1st line & Uniform & $\$ 0.70$ & $\$ 1.30$ & $\$ 1.00$ & MOHLTC:ODB: formulary [44] \\
\hline $\begin{array}{l}\text { Initial benzodiazepine } \\
\text { adjunctive 1st line }\end{array}$ & Uniform & $\$ 0.80$ & $\$ 1.49$ & $\$ 1.15$ & MOHLTC:ODB: formulary [44] \\
\hline $\begin{array}{l}\text { Initial benzodiazepine } \\
\text { monotherapy }\end{array}$ & Uniform & $\$ 0.10$ & $\$ 0.19$ & $\$ 0.15$ & MOHLTC:ODB: formulary [44] \\
\hline Initial 3rd line & Uniform & $\$ 0.83$ & $\$ 1.55$ & $\$ 1.19$ & MOHLTC:ODB: formulary [44] \\
\hline Maintenance 1st line & Uniform & $\$ 0.96$ & $\$ 1.78$ & $\$ 1.37$ & MOHLTC:ODB: formulary [44] \\
\hline $\begin{array}{l}\text { Maintenance } \\
\text { benzodiazepine } \\
\text { adjunctive 1st line }\end{array}$ & Uniform & $\$ 1.12$ & $\$ 2.07$ & $\$ 1.59$ & MOHLTC:ODB: formulary [44] \\
\hline $\begin{array}{l}\text { Maintenance } \\
\text { benzodiazepine } \\
\text { monotherapy }\end{array}$ & Uniform & $\$ 0.16$ & $\$ 0.30$ & $\$ 0.23$ & MOHLTC:ODB: formulary [44] \\
\hline Maintenance 3rd line & Uniform & $\$ 2.04$ & $\$ 3.79$ & $\$ 2.91$ & MOHLTC:ODB: formulary [44] \\
\hline Titrated 1st line & Uniform & $\$ 1.19$ & $\$ 2.20$ & $\$ 1.70$ & MOHLTC:ODB: formulary [44] \\
\hline $\begin{array}{l}\text { Titrated benzodiazepine } \\
\text { adjunctive 1st line }\end{array}$ & Uniform & $\$ 1.41$ & $\$ 2.63$ & $\$ 2.02$ & MOHLTC:ODB: formulary [44] \\
\hline $\begin{array}{l}\text { Titrated benzodiazepine } \\
\text { monotherapy }\end{array}$ & Uniform & $\$ 0.16$ & $\$ 0.29$ & $\$ 0.22$ & MOHLTC:ODB: formulary [44] \\
\hline Titrated 3rd line & Uniform & $\$ 4.04$ & $\$ 7.50$ & $\$ 5.77$ & MOHLTC:ODB: formulary [44] \\
\hline \multicolumn{6}{|l|}{ Indirect costs } \\
\hline $\begin{array}{l}\text { Absenteeism } 6 \text { months } \\
\text { (2 days/month) }\end{array}$ & Uniform & $\$ 1,465.12$ & $\$ 2,719.60$ & $\$ 2,092.72$ & Kessler [45]; Statistics Canada [46] \\
\hline
\end{tabular}


Table 3 continued

\begin{tabular}{llllll}
\hline Variable & Distribution & Low & High & Value & Source \\
\hline Resource use & & & & & \\
Treatment seeking rate & Triangular & 0.1000 & 0.3300 & 0.2600 & Wang [47] \\
Hospitalization rate & Triangular & 0.0000 & 0.1200 & 0.0600 & CIHI [43] \\
Discount rate & Uniform & 0.0000 & 0.0500 & 0.0500 & \\
\hline
\end{tabular}

CIHI Canadian Institutes of Health Information, MOHLTC Ministry of Health and Long Term Care, ODB Ontario Drug Benefit

Costs related to absenteeism were attributed to the assessment health states (i.e., "Family Physician", the two "Specialist Assessment Second-Line" and "Specialist Assessment ThirdLine"), as well as to patients in the "Treatment Discontinued" health state who have GADrelated symptoms but are not seeking treatment for the disorder (i.e., 1 minus the spontaneous remission rate). Patients in the four "Maintenance" health states were not attributed an indirect cost as the model assumed that while patients were in that health state, they were able to function effectively at work. However, it was assumed that patients not achieving "spontaneous remission" would be subject to impairment. Since indirect costs were measured as foregone wages, indirect costs were considered only for patients $\leq 65$ years of age.

\section{Discounting}

In accordance with the Canadian guidelines for economic evaluations of health technologies, costs were discounted at a rate of 5\% each year and altered to $0 \%$ in the sensitivity analysis [49].

\section{Variability and Uncertainty}

Computational validation of the model was performed through a "debugging" process [50].
A one-way sensitivity analysis was also performed to assess the impact of the parameter on the base case result. Breakdown analysis was performed to assess the impact of each variable on the base case result. The model structure was confirmed by an expert committee in the fields of mental health and health economics.

\section{RESULTS}

The mean value of the lifetime COI per patient with GAD was estimated to be (2008 CAD) $\$ 31,213$ (SD $\$ 9,100$ ). The distribution of COI values is illustrated in Fig. 3. The figure illustrates that nearly all of the cohort exited the model. The distribution of COI values is (visually) negatively skewed. However, using the formula for Pearson's index of skewness yields a value greater than -1.0 , suggesting that the data set is not significantly skewed, and that the mean and standard deviation are valid measures of central tendency and variability $(3 \times$ [mean - median $] /$ standard deviation $=3 \times$ $[\$ 31,213-\$ 33,855] / \$ 9,100=-0.87)$ [51].

The cost of absenteeism accounted for $96 \%$ of the mean COI. Pharmacotherapy contributed $1.8 \%$ to the lifetime COI, while physician fees contributed $1.5 \%$. Hospital costs and dispensing fees contributed a total of $0.5 \%$ to the expected COI. 


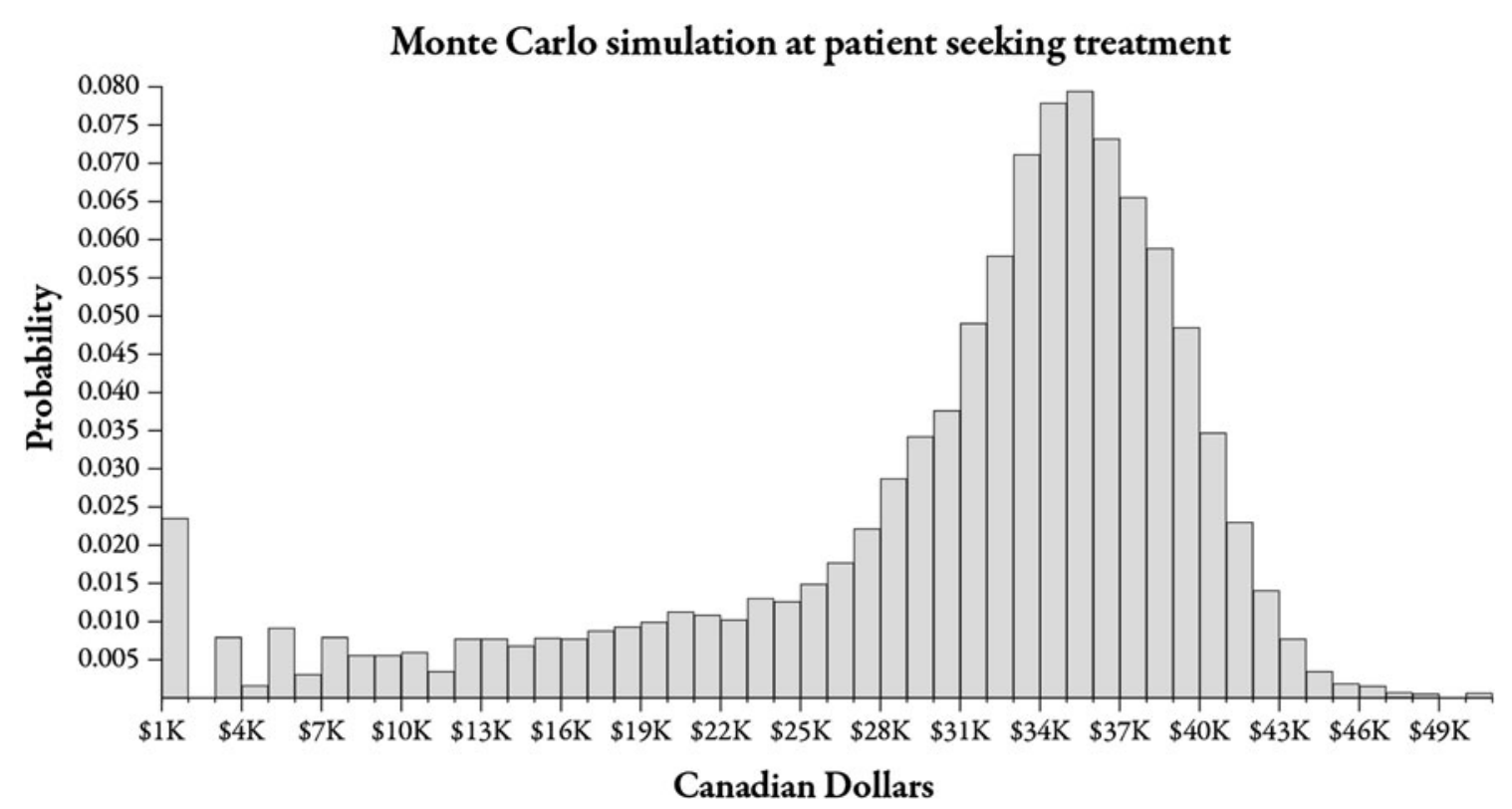

Fig. 3 Distribution of COI values from Monte Carlo simulation. COI cost of illness

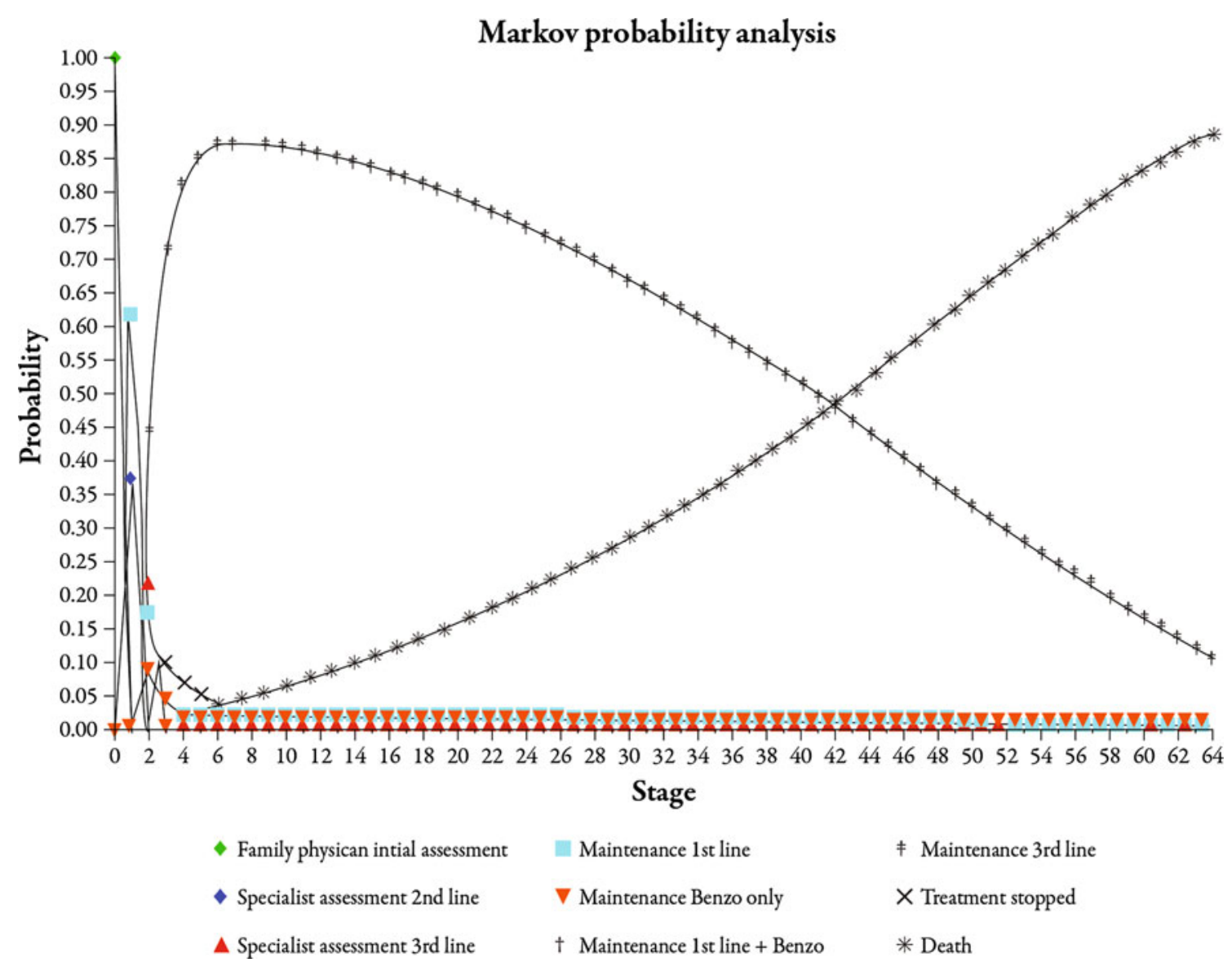

Fig. 4 Health-state cumulative transition probabilities graph. Benzo benzodiazepine 
Table 4 Epidemiologic parameters of study cohort

\begin{tabular}{lcccccc}
\hline Statistic & $\begin{array}{l}\text { Hospitalization } \\
\text { rate }\end{array}$ & $\begin{array}{l}\text { Relapse } \\
\text { per patient }\end{array}$ & $\begin{array}{l}\text { Relapse } \\
\text { rate }\end{array}$ & $\begin{array}{l}\text { Treatment } \\
\text { discontinuation } \\
\text { rate }\end{array}$ & $\begin{array}{l}\text { Treatment } \\
\text { resistant rate }\end{array}$ & $\begin{array}{l}\text { Years of } \\
\text { discontinued } \\
\text { treatment }\end{array}$ \\
\hline Mean & 0.01 & 0.79 & 0.53 & 0.98 & 0.19 & 14.41 \\
SD & 0.10 & 0.92 & 0.50 & 0.13 & 0.39 & 8.74 \\
Minimum & 0.00 & 0.00 & 0.00 & 0.00 & 0.00 & 0.00 \\
$2.5 \%$ CL & 0.00 & 0.00 & 0.00 & 1.00 & 0.00 & 1.00 \\
10.0\% CL & 0.00 & 0.00 & 0.00 & 1.00 & 0.00 & 3.00 \\
Median & 0.00 & 1.00 & 1.00 & 1.00 & 0.00 & 14.00 \\
$90.0 \% \mathrm{CL}$ & 0.00 & 2.00 & 1.00 & 1.00 & 1.00 & 27.00 \\
$97.5 \% \mathrm{CL}$ & 0.00 & 3.00 & 1.00 & 1.00 & 1.00 & 30.50 \\
Maximum & 1.00 & 7.00 & 1.00 & 1.00 & 1.00 & 31.50 \\
\hline
\end{tabular}

$C L$ confidence limit

Health state probabilities are presented in Fig. 4 . The mean age at which patients entered the model was 31 years. Eighty-nine percent of the patients who entered the model died from all causes, thereby exiting the model. Approximately $11 \%$ of the cohort remained in the model at some point during their expectant lifespan upon completion of the simulation. Just over $85 \%$ of patients stopped treatment by the fourth cycle (year 2). Over the course of the model, a mean of $53 \%$ of patients relapsed, with an average rate of 0.79 relapses per patient. Approximately $19 \%$ of patients did not respond to any pharmacotherapeutic agent. The mean length of time during which patients were not managed for GAD was 14 (SD 9) years. The mean rates of epidemiologic parameters are presented in Table 4.

\section{Sensitivity Analysis}

The COI was most sensitive to the cost of absenteeism. The range of uncertainty for the cost of absenteeism was $\$ 1,465-\$ 2,720$ and it exerted the highest impact compared to all other variables, varying the COI between $\$ 20,500$ and $\$ 37,500$. The mean COI result was robust against reasonable variations in all other cost variables, with mean COI values maintained at approximately $\$ 31,000$. The range of uncertainty for clinical variables was narrower overall $(\$ 30,000-\$ 32,000)$ compared to economic variables $(\$ 20,500-\$ 37,500)$. Spontaneous remission exerted the most uncertainty, varying the mean COI by approximately $\$ 2,000$, with the remaining variables varying the mean COI by $\$ 200$ or less.

\section{Subanalysis}

The addition of ten sessions of CBT therapy to existing pharmacotherapy resulted in minimal impact on the COI. Adding ten sessions of CBT to the first-line assessment health state added $0.7 \%$ to the lifetime COI. If CBT were to be added during the second or third-line assessment health state, the additional cost increased by $0.3 \%$ and $0.01 \%$, respectively. 


\section{DISCUSSION}

Arguably, the mean COI result in the present study is a conservative estimate. This study used 2 days of lost productivity or absenteeism to derive the COI. Recent studies have shown lost productivity or absenteeism at 3 days or more $[52,53]$. Use of a higher "days of lost productivity" would in turn produce a higher point estimate for the authors' mean COI. Furthermore, costs related to absenteeism or loss of leisure time, were not attributed to patients over the age of 65 years. This too would have a conservative impact on the authors' COI point estimate.

The COI was not sensitive to physician or pharmacist fees or drug costs. The distributions for physician and pharmacist fees incorporated a wider range of uncertainty $( \pm 30 \%$ of the likeliest value) than those published in the Ontario Schedule of Benefits. However, pharmacist fees may be higher than the upper range of uncertainty in some Canadian provinces. Furthermore, the estimated daily cost for agents excluded from this study is largely within the range of costs for second-line therapy used in this model, and it is unlikely that consideration of these agents would have a significant impact on the mean COI.

There are no previous publications of models reflecting the lifetime course of GAD and its cost to society. Previous economic evaluations of GAD were either cross-sectional or prevalence-based in design and estimated the healthcare costs over the short-term only. As such, comparison of study outcomes should be undertaken with caution. One economic evaluation limited the assessment of cost to medical expenses, estimating that GAD incurred a marginal mean cost of US $\$ 2,138$ (95\% CI \$1,641, \$2,632) compared to patients with no GAD [51]. These data were collected and derived over a 1-year period in a cohort taken from a healthcare charges database [54]. In contrast, depression incurred a marginal mean cost of US\$1,944 and panic disorder incurred a marginal mean of US\$1,603, compared to patients that did not suffer from either condition [54]. The only anxiety disorder in the study of Marciniak et al. [54] to have incurred a higher marginal mean cost was posttraumatic stress disorder. Another study found similar results, showing a significantly higher median medical care charges in patients with GAD than those with no GAD $(\$ 2,375$ vs. $\$ 1,448$ ) [55]. Moreover, there is general agreement that all anxiety disorders are underdiagnosed and undertreated [31, 47, 56-60]; thus, limiting the usefulness of either population based studies or COI studies using healthcare charges alone. Furthermore, neither productivity nor absenteeism was incorporated into the estimation of the cost of GAD in either of the above-mentioned COI studies.

The use of a Markov decision analytic framework in this study allows for the consideration of chronicity as well as for the waxing and waning of symptoms. Furthermore, the model could easily be adapted to estimate cost-effectiveness by adding a second branch comparing a novel therapeutic (e.g., duloxetine) to existing treatment options. While prior to this study, there was no Markov model for an economic evaluation of a patient with GAD, a Markov cost utility analysis for the treatment of major depressive disorder has been published. In that study, the mean annual total medical cost for escitalopram was US\$907 and US $\$ 1,633$ for duloxetine [61].

No previous studies have reported treatment patterns prescribed for GAD patients or what access they have to therapists in a Canadian setting. Therefore, a comparison of the estimated mean COI to one that would reflect 
"real-life" management of GAD is not possible. The subanalysis determined that combination therapy would not have a substantial economic impact to the COI.

Relapse rates for this study were derived from a study by Yonkers et al. [36] who reported cumulative relapse rates over an 8-year followup period. The relapse rate used in this study was elected assuming that a weighted mean relapse rate could be extrapolated on to a longer time horizon. In a sensitivity analysis, the COI was not sensitive to the relapse rate and, therefore, does not introduce a substantial bias either way.

\section{Limitations}

Lack of available sources reporting both clinical and resource utilization data was a significant limitation to this study. Of note, remission rates for benzodiazepines were scarce primarily due to the quality of reporting. Discontinuation rates for benzodiazepines were derived from a persistence rate and none were available for third-line treatment. Furthermore, there are no available data regarding the Canadian utilization patterns of drugs by GAD patients.

GAD patients often present with somatic symptoms, such as pain, cardiac, and gastrointestinal symptoms, but more so during initial contact, with resulting investigations for mental illness [47, 54-56]. A reasonable assumption, therefore, is that prior to a primary diagnosis of GAD, patients are referred to one or more specialists for further assessment of their somatic symptoms. While this assumption is supported by several studies [47, 56-60], costs leading up to a clinical assessment of GAD were not considered in this study, and the authors speculate that this issue also contributes to a conservative estimate of the COI. Nevertheless, further study that focuses on costs leading up to a clinical diagnosis of GAD would significantly contribute to the existing literature.

There were no Canadian data on utilization patterns of drugs included in the treatment lines. Therefore, a comparison of mean daily costs for medication could not be validated. However, in this study, COI was not sensitive to drug costs. Therefore, it is likely that this lack of data did not contribute to the uncertainty of the estimate.

One other limitation of the present research is that it encompasses treatment for GAD only, excluding any treatment for any other form of comorbid condition, such as depression, which is highly prevalent in GAD. Even though treatment modalities in associated mental diseases may overlap, the authors' COI estimates are restricted to the studied population and extrapolations to comorbid GAD require cautious interpretation.

\section{CONCLUSION}

In conclusion, based on this COI, the estimated burden of illness of GAD in Canada ranges between $\$ 397,488,000$ and $\$ 944,034,000$. This estimated range is based on a lifetime prevalence rate of $2.4-5.7 \%$ and 26 million people over the age of 15 years in Canada in 2006. As previously discussed, the authors believe this to be a conservative estimate. Comparison of the burden of illness between studies should be undertaken with extreme caution, given the variability of methods and variables included in the analysis. However, the economic burden of illness for 1998, published by Health Canada, reports total costs (direct and indirect) for mental disorders at $\$ 7.9$ billion dollars. Discounting the 2008 burden of illness at 5\% per annum, yields a discounted estimate between $\$ 244,022,000$ and $\$ 579,553,070$. 
Again, with caution, one may infer that GAD contributes between $3.1 \%$ and $7.3 \%$ to the burden of mental health in Canada.

Given the above limitations, this model reflects the long-term course of GAD, providing a reasonable estimate of its societal impact. From a societal perspective, absenteeism exerts a significant impact to the cost of illness of GAD. A lack of prospective clinical data contributes to the uncertainty of the COI estimate.

Future investigations of this model using prospective data would be valuable. Research determining which therapies are most efficacious given patient and disease characteristics, such as severity of GAD, age of patient, or for treatment resistant patients, may improve the estimate of the COI of GAD. Furthermore, research into the societal cost of GAD prior to the primary diagnosis would also provide insight into a more precise estimate of the cost of GAD from a societal perspective. Resource utilization of Canadian treatment patterns for GAD would also be useful to estimate COI and to assess whether guidelines are followed.

\section{ACKNOWLEDGMENTS}

This manuscript and the underlying study were written and conducted as part the first author's graduate studies requirements at the Graduate Faculty of Pharmaceutical Sciences, University of Toronto. B.G.B. is the guarantor for this article, and takes responsibility for the integrity of the work as a whole.

Conflict of interest. The authors confirm that no direct conflicts of interest exist. No external funding was received for this project. M.M. is currently the Pharmacoeconomics Manager at GlaxoSmithKline Brazil.
Open Access. This article is distributed under the terms of the Creative Commons Attribution Noncommercial License which permits any noncommercial use, distribution, and reproduction in any medium, provided the original author(s) and source are credited.

\section{REFERENCES}

1. García-Altés A, Ondategui-Parra S, Neumann PJ. Cross national comparison of technology assessment processes. Int $\mathrm{J}$ Technol Assess Healthcare. 2004;20:300-10.

2. Jacobi F, Wittchen H-U, Holting C, et al. Prevalence, co-morbidity and correlates of mental disorders in the general population: results from the German Health Interview and Examination Survey (GHS). Psychol Med. 2004;34:597-611.

3. Grant BF, Hasin DS, Stinson FS, et al. Prevalence, correlates, co-morbidity, and comparative disability of DSM-IV generalized anxiety disorder in the USA: results from the National Epidemiologic Survey on Alcohol and Related conditions. Psychol Med. 2005;35:1747-59.

4. Bereza BG, Machado M, Einarson TR. Systematic review and quality assessment of economic evaluations and quality of life studies related to generalized anxiety disorder. Clin Ther. 2009;31: 1279-308.

5. Kessler RC, Berglund P, Demler O, et al. Lifetime prevalence and age-of-onset distributions of DSM-IV disorders in the National Comorbidity Survey Replication. Arch Gen Psychiatry. 2005;62:593-602.

6. Kessler RC, Chiu WT, Demler O, et al. Prevalence, severity, and comorbidity of 12-month DSM-IV disorders in the National Comorbidity Survey Replication. Arch Gen Psychiatry. 2005;62:617-27.

7. Offord DR, Boyle MH, Campbell D, et al. One-year prevalence of psychiatric disorder in Ontarians 15 to 64 years of age. Can J Psychiatry. 1996;41: 559-63.

8. Hales RE, Yudofsky SC, editors. The american psychiatric publishing textbook of clinical psychiatry. 4th ed. Arlington: American Psychiatric Publishing Inc.; 2003.

9. Sadock BJ, Sadock VA, editors. Kaplan \& Sadock's comprehensive textbook of psychiatry. 8th ed. New York: Lippincott Williams \& Wilkins; 2005. 
10. Diagnostic and statistical manual of mental disorders. 4th ed. Washington, DC: American Psychiatric Association; 1994.

11. World Health Organization. The ICD-10 classification of mental and behavioral disorders: clinical description and diagnostic guidelines. Geneva: WHO; 1993.

12. Canadian Psychiatric Association. Clinical practice guidelines: management of anxiety disorders. Can J Psychiatry. 2006;51:S1-92.

13. von Neumann J, Morgenstern O. Theory of games and economic behavior. Princeton: Princeton University Press; 1947.

14. Elwyn G, Edwards A, Eccles M, Rovner D. Decision analysis in patient care. Lancet. 2001;358:571-4.

15. Government of Canada. Human resources and skills development Canada web site accessed (life expectancy). http://www4.hrsdc.gc.ca/.3ndic.1t.4r@. jsp?iid=3\#m_1. Accessed Mar 17, 2009.

16. Le Roux H, Gatz M, Wetherall JL. Age at onset of generalized anxiety disorder in older adults. Am J Geriatr Psychiatry. 2005;13:23-30.

17. Statistics Canada. Complete life table, Canada, 2000 to 2002: (all cause mortality) males: http://www.statcan.gc.ca/pub/84-537-x/t/txttables/ cam.txt; females: http://www.statcan.gc.ca/pub/ 84-537-x/t/txttables/caf.txt. Accessed Mar 17, 2009.

18. Statistics Canada. Gender proportion. http://www 12.statcan.gc.ca/census-recensement/2006/dp-pd/ tbt/Rp-eng.cfm?LANG $=$ E\&APATH $=3 \& D E T A I L=0 \&$ $\mathrm{DIM}=0 \& \mathrm{FL}=\mathrm{A} \& \mathrm{FREE}=0 \& \mathrm{GC}=0 \& \mathrm{GID}=0 \& \mathrm{GK}=0 \&$ $\mathrm{GRP}=1 \& \mathrm{PID}=88977 \& \mathrm{PRID}=0 \& \mathrm{PTYPE}=88971,97154$ $\& S=0 \& S H O W A L L=0 \& S U B=0 \&$ Temporal $=2006 \&$ THEME $=66 \& V I D=0 \& V N A M E E=\& V N A M E F=$. Accessed Mar 17, 2009.

19. Product Monograph: Alprazolam. Laval: ProDoc Lté; 2003.

20. Product Monograph: Diazepam. Mississauga; Hoffmann-La Roche Ltd.; 2007.

21. Prescribing Information: Lorazepam. St. Laurent: Wyeth Canada; 2003.

22. Product Monograph: Apo-Paroxetine. Weston: Apotex Inc.; 2007.

23. Product Monograph: Co-Sertraline. Mississauga: Cobalt Pharmaceuticals Inc; 2006.

24. Product Monograph: Escitalopram. Montreal: Lundbeck Canada Inc.; 2008.
25. Product Monograph: Venlafaxine. Montreal: Wyeth Canada; 2009.

26. Product Monograph: Bromazepam. Mississauga: Hoffmann-La Roche Ltd.; 2007.

27. Vasile RG, Bruce SE, Goisman RM, Pagano M, Keller MB. Results of a naturalistic longitudinal study of benzodiazepine and SSRI use in the treatment of generalized anxiety disorder and social phobia. Depress Anxiety. 2005;22:59-67.

28. Varia I, Rauscher F. Treatment of generalized anxiety disorder with citalopram. Int Clin Psychopharmacol. 2002;17:103-7.

29. Pollack MH, Simon NM, Zalta AK, et al. Olanzapine augmentation of fluoxetine for refractory generalized anxiety disorder: a placebo controlled study. Biol Psychiatry. 2006;59:211-5.

30. Gambi F, De Berardis D, Campanella D, et al. Mirtazapine treatment of generalized anxiety disorder: a fixed dose, open label study. J Psychopharmacol. 2005;19:483-7.

31. Gwynn RC, McQuistion HL, McVeigh KH, Garg RK, Frieden TR, Thorpe LE. Prevalence, diagnosis and treatment of depression and generalized anxiety disorder in a diverse urban community. Psychiatr Serv. 2008;6:641-7.

32. Machado M, Iskedjian M, Ruiz I, Einarson TR. Remission, dropouts, and adverse drug reaction rates in major depressive disorder: a meta-analysis of head-to-head trials. Curr Med Res Opin. 2006;22:1825-37.

33. Bereza BG, Machado M, Ravindran AV, Einarson TR. Evidence based review of clinical outcomes of guideline recommended pharmacotherapies for generalized anxiety disorder (GAD). Can J Psychiatry (in press).

34. Mullins CD, Shaya FT, Fanlun M, Wang J, Harrison D. Persistence, switching, and discontinuation rates among patients receiving sertraline, paroxetine, and citalopram. Pharmacotherapy. 2005;25:660-7.

35. Ohayon MM, Caulet M, Priest RG, Guilleminault C. Psychotropic medication consumption patterns in the UK general population. J Clin Epidemiol. 1998;51:273-83.

36. Yonkers KA, Bruce SE, Dyck IR, Keller MB. Chronicity, relapse and illness course of panic disorder, social phobia, and generalized anxiety disorder: Findings in men and women form 8 years of follow up. Depress Anxiety. 2003;17:173-9.

37. Ballenger J, Davidson J, Lecrubier $\mathrm{Y}$, et al. Consensus statement on generalized anxiety 
disorder from the international consensus group on depression and anxiety. J Clin Psychiatry. 2001;62: 53-8.

38. Martin JLR, Sainz-Pardo M, Furukawa TA, MartinSanchez E, Seone T, Galan C. Benzodiazepines in generalized anxiety disorder: heterogeneity of outcomes based on a systematic review and metaanalysis of clinical trials. J Psychopharmacol. 2007;21:774-82.

39. Einarson TR. Pharmacoeconomic applications of meta-analysis for single groups using antifungal onychomycosis lacquers as an example. Clin Ther. 1997;19:559-69.

40. Minister of Health and Long Term Care web site. Ontario drug benefit: dispensing fee. http:// www.health.gov.on.ca/english/public/pub/drugs/ dispense.html. Accessed Apr 18, 2009.

41. Minister of Health and Long Term Care web site. Schedule of benefits for physician services under the Health Insurance Act. http://www.health.gov. on.ca/english/providers/program/ohip/sob/physserv/ physserv_mn.html. Accessed Apr 18, 2009.

42. Health Canada. A report on mental illnesses in Canada. Ottawa, Canada 2002. http://www.hc-sc. gc.ca/pphb-dgspsp/publicat/miic-mmac/index.html, http://www.phac-aspc.gc.ca/publicat/miic-mmac/ pdf/chap_4_e.pdf. Accessed Apr 18, 2009.

43. Canadian Institute for Health Information (CIHI). Estimation of total acute care inpatient costs, with average cost per stay (unit cost), 2004-2005. http://dsp-psd.pwgsc.gc.ca/collection_2008/cihi-icis/ H115-39-2005E.pdf. Accessed Mar 13, 2009.

44. Minister of Health and Long Term Care web site. Formulary search. https://www.healthinfo.moh.gov. on.ca/formulary/. Accessed Apr 18, 2009.

45. Kessler RC, DuPont RL, Berglund P, Wittchen H-U. Impairment in pure and co-morbid generalized anxiety disorder and major depression at 12 months in two national surveys. Am J Psychiatry. 1999;156: 1915-23.

46. Statistics Canada. Wage rate: http://www.statcan.gc.ca/ tables-tableaux/sum-som/101/cst01/labr69a-eng.htm. Accessed Apr 18, 2009.

47. Wang PS, Lane M, Olfson M, Pincus HA, Wells KB, Kessler RC. Twelve-month use of mental health services in the United States: results from the National Comorbidity Survey Replication. Arch Gen Psychiatry. 2005;62:629-40.

48. Statistics Canada. Consumer price index. http:// www.statcan.gc.ca/tables-tableaux/sum-som/101/ cst01/econ46a-eng.htm. Accessed Apr 18, 2009.
49. Canadian Agency for Drugs and Technologies in Health. HTA; Guidelines for the Economic Evaluation of Health Technologies: Canada. 3rd ed. Ottawa: Canadian Agency for Drugs and Technologies in Health; 2006.

50. Krahn M, Naglie G, Naimark D, Redelmeier D, Detsky A. Primer on medical decision analysis: part 4-Analysing the model and interpreting the results. Med Decis Making. 1997;17:142-51.

51. Wilson EB. Probable inference, the law of succession, and statistical inference. J Am Stat Assoc. 1927;22:209-12.

52. Alonso J, Petukhova M, Vilagut G, et al. Days out of role due to common physical and mental conditions: results from the WHO World Mental Health Surveys. Mol Psychiatry. 2010;16:1234-46.

53. Merikangas KR, Ames M, Cui L, et al. The impact of comorbidity of mental and physical conditions on role disability in the US adult household population. Arch Gen Psychiatry. 2007;64:1180-8.

54. Marciniak MD, Lage ML, Dunayevich ED, et al. The cost of treating anxiety: the medical and demographic correlates that impact total medical costs. Depress Anxiety. 2005;21:178-84.

55. Olfson M, Gameroff MJ. Generalized anxiety disorder, somatic pain and healthcare costs. Gen Hosp Psychiatry. 2007;29:310-6.

56. Schulberg HC, McClelland M, Coulehan JL, Block M, Werner G. Psychiatric decision making in family practice future research directions. Gen Hosp Psychiatry. 1986;8:1-6.

57. Wittchen H-U. Generalized anxiety disorder: prevalence, burden, and cost to society. Depress Anxiety. 2002;16:1622-710.

58. Roy-Byrne P, Wagner A. Primary care perspectives on generalized anxiety disorder. J Clin Psychiatry. 2004;65(Suppl. 13):20-6.

59. Logue MB, Thomas AM, Barbee JG, et al. Generalized anxiety disorder patients seek evaluation for cardiological symptoms at the same frequency as patients with panic disorder. J Psychiatr Res. 1993;27:55-9.

60. Walker EA, Roy-Byrne PP, Katon WJ, et al. Psychiatric illness and irritable bowel syndrome: a comparison with inflammatory bowel disease. Am J Psychiatry. 1990;147:1656-61.

61. Armstrong EP, Malone DC, Haim Erfer M. A Markov cost-utility analysis of escitalopram and duloxetine for the treatment of major treatment disorder. Curr Med Res Opin. 2008;24:1115-21. 